\title{
Examining International Education Research and Practice through a Queer Theory Lens
}

\section{Stephen Louis Capobianco \\ Binghamton University}

\begin{abstract}
:
In this critical essay, the author explores the pronounced lack of attention to the intersection of LGBTQI+ people and issues in international education. By presenting and then employing a conceptual framework that combines a queer theoretical lens and a multi-level analysis of structural contexts, the author examines the existing body of literature and practice on the nexus of LGBTQI+ inclusion and international education in institutions of higher education. Through the use of this combined conceptual framework, the author introduces a path forward to build a more inclusive field of international education for all by discussing implications for practice and recommendations for future areas of research.
\end{abstract}

\section{Introduction}

Despite the increasing emphasis on promoting internationalization (Hegarty, 2014; Institute of International Education, 2018a), on increasing the number of students engaged in international education (Institute of International Education, 2017a, 2017b), and on diversifying student participation (Institution of International Education, 2018b), the intersection of LGBTQI+ issues within international education converges key aspects of inclusion-based interventions for practice and research. The discourse on equality and internationalization in higher education further reflects this inattention with respect to the LGBTQ+ community (Jubas, 2015). This critical essay probes how scholars and practitioners can use a queer theoretical framework and structural analysis to investigate inclusivity within the field of international education for the LGBTQI+ community as a means to both inform institutional practice and further scholarship. Although the topic of LGBTQI+ college students has been, and continues to be, widely addressed in higher education literature (Atteberry-Ash \& Woodford, 2018; Carpenter, 2008; Mayo, 2007; Rankin, 2003; Stewart \& Kendrick, 2019; Teman \& Lahman, 2012), little empirical research focuses on organizational issues or policy within higher education using a queer theory framework (Renn, 2010), which exposes a gap in our practice and scholarly research. This essay extends the examination of this gap to the field of international education within higher education.

International education involves working with students, staff, faculty, and international partners of diverse backgrounds from all over the world. This work necessarily requires attention to issues of diversity of identity and community. In order to attain the aforementioned goal of expanding international learning experiences to all students, the field must take into account the intersections of identities that many students bring to their education, including those of diverse populations, such as LGBTQI+ persons. As a first step, understanding the number of people that identify as LGBTQI+ is vital to collective community action and representation within higher education 
institutions. It is difficult, however, to ascertain percentages of the population that identify as LGBTQI+, but estimates show they make up a substantial minority. In a study for the Williams Institute at UCLA School of Law, Gates (2011) found that there are around 9 million adults or 3.5\% of the adult population in the United States who identify as LGBT and in 2016 poll published by Gallup News, Gates (2017) estimates that $4.1 \%$ or 10 million U.S. adults identify as LGBT. Although there is no concrete data on how many students in higher education identify as LGBT, the same Williams Institute predicts, from the Gallup Daily tracking data, that 34\% of both LGBT and nonLGBT persons have a college education (Same-sex couple and LGBT demographic data interactive, 2016). Therefore, it is likely that there are hundreds of thousands of students in universities across the United States who identify as LGBTQI+ out of around 20.4 million students enrolled in Fall 2017 (National Center for Education Statistics, 2017). Higher education in particular fosters a positive impact on LGBTQI+ students' identity development (Bilodeau \& Renn, 2005; Torres, Jones, Renn, 2009). Harassment and discrimination, however, remain problems that affect LGBT students' learning and wellbeing (Rankin, 2003). Therefore, it is imperative to critically review campus climate, including international programs, as it can have negative consequences on students' learning and wellbeing, as found by Hurtado, Griffin, Arellano and Cuellar's (2008) review of campus climate research and instruments.

My search (conducted in early 2019) for current scholarly literature regarding LGBTQI+ issues in international education yielded scant results, so the field has significant room to grow in terms of paradigmatic approaches, methodology, and practice. A significant body of literature on LGBTQI+ university students exists (Carpenter, 2008; Mayo, 2007; Rankin, 2003; Teman \& Lahman, 2012), but my focus here is constrained to literature on student mobility and engagement in international education initiatives, such as study abroad and degree-seeking international students in North America. Despite so few published articles, the contributions of this research and the gaps outlined in this critical essay serve as a springboard for further inquiry and suggest resistance against the dominant heteronormative framework of viewing the world.

\section{Benefits of a Queer Theoretical Lens}

Although some scholars focus on LGBTQI+ issues in international education, no scholars specifically adopt a queer theoretical lens to examine these issues, which limits their impact on discourse, especially in terms of evaluating the lived experiences of queer individuals vis-à-vis international education. Renn's (2010) literature review on the state and status of queer research in higher education specifically calls for additional research in this field: "the areas of globalization and internationalization of higher education are ripe for infusing LGBT issues" (p. 138). In this article, I present and critique the current state of scholarly production on this topic. Based on my reading of the literature through a combined framework of a queer theoretical lens and praxis and a cross-level structural analysis, I aim to prompt implications for future practice and research.

Further research on LGBTQI+ people and issues in international education serves the profession because of internationalization's general claim to bring the world to the students and the students to the world (e.g. Capobianco, Chen, Lippez-De Castro \& Rubaii, 2018; Knight, 2004; Larsen \& Searle, 2017; Ziemba, Sarkar, Pickus, Dallwig, Wan \& Alcindor, 2016). If the field of higher education scholarship continues to perpetuate the marginalization of the LGBTQI+ population by not including them in the discourse, then the current unequal state of power relations 
between the heteronormative structure and institutions and those who have been and continue to be marginalized will continue to dominate (Jubas, 2015, Jubas \& White, 2017). By continuing to keep LGBTQI+ people and issues outside of the peer-reviewed scholarship in international education, the academy and profession, at best, unconsciously erases their existence and, at worst, purposefully oppresses queerness. Research in this area will contribute to the emerging scholarly dialogue on these themes and potentially uncover future areas for university practice to improve the quality of international education.

Due to this marked lack of scholarly focus on issues regarding LGBTQI+ people and issues in international education, this critical essay will contribute to better understanding the structural context of this intersection of international education and diversity. Using a combined framework of a queer theoretical lens and a structural analysis to examine existing literature and practice on LGBTQI+ inclusion in international education, the present work seeks to identify avenues for further practice and research on how to better support students who identify as LGBTQI+ as they engage in international education.

\section{Definitions}

Throughout this essay, I use LGBTQI+ as the term not only for individuals who identify as lesbian, gay, bisexual, transgender, queer or questioning, but also for those who may not identify with those labels, but with a different non-heteronormative or non-cisnormative label of their own sexual orientation or gender identity. I use this acronym as an inclusive term to represent the people who identify with the shared history of struggle against heteronormative and binary modes of being and thinking of humanity. Throughout the essay, I use the broadly encompassing label LGBTQI+; when I use the more conventional and narrower label LGBT it is because the source materials I am referencing are limited in that way. At times I also use the word queer to envelop the community together as an act of banding together in opposition to stigmatization, discrimination, and violence (Luther, 2017).

\section{Reflexivity}

Like other scholars engaged in research justice, for example Smith (2015), Fine $(2015,2018)$, and Blalock (2015), I would like the opportunity to position myself in the space of research and action. In doing so, I recognize that my own lived experiences and personal identities are relevant to this topic and should not be ignored. I am not an outsider to this field of international education, but rather I have dedicated large portions of my professional life and scholarly work toward it. I have worked both at the Office for International Programs at Binghamton University and in the Office of Global Learning at Cornell University, which offered me a certain level of professional insight into the field and practice of international education. Consequently, I saw, and worked within, the day-to-day activities of an international education office. I interacted with students, staff, faculty, third-party providers, and foreign partners on a daily basis. In guiding the international experiential component for students at the Institute for Genocide and Mass Atrocity Prevention, I am in a position to ensure that diversity, equity, and inclusion are considered and prioritized. I am, also, proud to identify as a member of the Queer community, which can be a dangerous thing to write depending on where in the world I may be or who may be reading this. Additionally, I believe that we should break apart the constraints of categorization of sexual and gender labels that are remnants of heteronormative oppression. Sedgwick (1990) reminds us, however, it is important to 
join together in a collective community of similar lived experiences, self-identities, and socially imposed identities in order to fight against these oppressions.

From personal experiences speaking with students, staff, faculty, and international partners, I have noticed a palpable need to acknowledge the LGBTQI+ experience in international education as a distinct intersection worthy of scholarly attention within the field. These conversations echo within my experiences attending international education conferences and sessions on diversity and inclusion. Indeed, I think it is crucial that someone step up to the task of melding academic rigor and queer voices and experiences. International education seeks to build a platform for human-tohuman exchange and move the world in a more peaceful and equitable direction (Curtis \& Ledgerwood, 2018; Deardorff, 2017). I share the opinion of scholars such as Berghman (1995), who deems it impossible to reach this admirable goal when marginalized groups are kept silent or unrepresented. So, in this space and time I will use my scholar, practitioner, and activist identities to expand our knowledge on inclusion for LGBTQI+ individuals and communities within international education and hold a mirror to it as a way forward to a more just future.

\section{Problem statement}

Queer representation in the practical field of international education forms the basis of this essay. As I have noted, international education is ripe for an analysis and critique of its practice and research with respect to queer inclusion. Within this essay, I use insights from queer theory as both a critical lens of understanding and being in the world and as a praxis for social change and transformation of the current world into a safer, kinder, more equitable place for all people on the margins of our heteronormative societies. Being queer resists dominant ways of thinking and existing, and rejects heteronormativity, which confines and defines what is normal and right (Collins \& Bilge, 2016; Haiven \& Khasnabish, 2014; Zeffiro \& Hogan, 2015). Therefore, by placing this essay within a queer theoretical framework, I connect with a more ambitious framework of fighting against injustice by not only critiquing current structures and questioning what is normal, but also by uncovering potentially new approaches to policy, practice, and research.

Contested and shifting paradigms of study, both in terms of seeing and understanding the world and in terms of knowledge production, form the backdrop of the present work. The result of this contention, however, is a time of liberation from the cemented earlier approaches to thinking about the world and about the human being experience. Lincoln, Lynham, and Guba (2017) deem it, "emancipation from generations of silence, and emancipation from seeing the world in one color" (p. 145). In critical social research and practice, space needs to be created and time taken for queer voices and representations to be brought to the surface and move from the silence of the margins toward the center. I invoke the mercurial qualities of a queer theoretical lens and its subversive characteristics to critically expose the normative structures of our social realities within international education, but more broadly to question the human condition.

The multiplicity of ways that queer theory can be employed conveys the power of such a framework. Queer theory acts as a critical lens, like Alexander (2017) proposes, through which the "regimes of the normal" are critiqued on behalf of and by people on the margins (p. 278). At the same time, queer theory pushes community research and action, as a vehicle, to interrupt the hegemonic and dominant power structures which queerness seeks to destabilize. It is both a method of queer 
meaning-making, of seeing and experiencing life from a non-dominant position, but also in queer world-making, which demands action and transformative change beyond the pragmatic realm of political rights toward envisioning a new world without oppression and exclusion (Muñoz, 2009; Alexander, 2017). Through developing internal queer community knowledge and offering a platform to share that knowledge, marginalized peoples both have a voice and simultaneously create impetus for social change (Zeffiro \& Hogan, 2015). In queer social movements, it is crucial that this knowledge and the subsequent acts of resistance to dominant paradigms connect with one another. Medina (2013) identifies the powerful and impactful echoing effects of acts of resistance and proposes the idea of a social network of resistance. Others engage with these acts and then repeat them in similar patterns, ultimately leading to transformation and social change. Therefore, it is here, within an approach to research and practice grounded in queer theory, where both the critical lens of queer meaning-making and the social change of queer world-making come together in a tangible way.

An overarching theme in this type of analysis is the use of the process of research and its effects both to improve lives and to transform the social organization of international higher education. This methodology therefore integrates itself within the radical notions of queer theory in producing a new and better world for all (Muñoz, 2009). A queer theoretical framework allows an individual to tap into the actionable space of political change and to challenge the dominant frameworks of research, institutions, and ways of being in the world. Zeffiro and Hogan's (2015) definition, "to queer (verb) is to challenge the assumptions, boundaries, and biases that are taken as neutral indicators that "this is the way things should be," offers a way forward for queer research to look for alternatives to existing conditions (p. 46-47). My arguments here is not only to produce new knowledge for the field of international education and enhance global learning initiatives, but to give space and time to the people who may be marginalized in the processes of global mobility in higher education.

\section{Conceptual Framework}

In this section, I present and describe the two overarching theoretical lenses, a queer theoretical perspective and an analysis of structural levels, as I use them in this essay. The integration and overlay of these two theoretical lenses provides a conceptual framework that I use for exploring the current state of LGBTQI+ inclusion in international education. This framework sets the stage for reading and interpreting the existing literature and practices on LGBTQI+ people and issues in international education. It structures both the basis of my analysis herein for inclusive future practice and research and the foundation for use by other practitioners and scholars. The integration of these two theoretical lenses allows for a distinctive critique of the levels of systems and relationships that operate in international education with respect to the normative positions or actions that marginalize LGBTQI+ individuals.

\section{A Guiding Lens: A Queer Theoretical Perspective}

Queer theory does not belong to one author or one book, but rather brings together a theoretical framework to understand how the structural inequalities of society act and control the lives of those on the margins (Alexander, 2017; Foucault, 1978; Halberstam, 2011; Muñoz, 1999, 2009; Medina, 2013; Sedgwick, 1990; Zeffiro \& Hogan, 2015). Queer theory, as an interpretive paradigm, has been used to examine the effects of societal power on non-normative individuals and 
communities, especially those on the margins, such as LGBTQI+ people (Alexander, 2017; Muñoz, 2009; Zeffiro \& Hogan, 2015). The importance of the interrogation of this process emerges as notions of equality are reinterpreted and selectively cover some parts of the population over others. Using queer theory as a lens pushes the analysis of individual and community marginalization beyond a framework of equality and toward a radically transformative understanding of the interaction between individuals, communities, organizations, and state powers (Medina, 2013; Zeffiro \& Hogan, 2015).

A queer theoretical framework also creates space to challenge the paradoxes of essentialism and constructivism; that is, the ideas that suggest that we are always bound to certain inherent characteristics, and our identities are socially constructed (Foucault, 1978; Medina, 2013; Sedgwick, 1990). There is a delicate balance between uplifting voices marginalized due to structural inequalities, such as those who identify with the LGBTQI+ community, while simultaneously avoiding the tendency to essentialize an individual's thoughts, desires, and actions into inherent categories (Medina, 2003, p. 299). The affinity of the queer theoretical lens towards problematization offers not only new sites of inquiry into the effects of these structural inequalities, but also offers the opportunity for collective action across marginalized groups toward common goals of positive social change.

Moreover, focusing on queer lives and queer experience then becomes a way to combat the imposed rigidity of normalized sexuality, power structures, and societal control over individuals that originates from categorization. At times, this resistance requires identifying with a queer community in order to normalize non-dominant persons within controlling power structures and build toward political progress (Sedgwick, 1990, p. 58). Herein lies another paradox: in order to achieve sociopolitical progress, in terms of individual freedoms from heteronormativity, collective identification and organization as a group are necessary (Stone, 2012, p. 334). Scholarly research that approaches the topic by highlighting experiences and stories of LGBTQI+ people and allies working toward inclusivity, both individually and collectively, thereby constitutes a form of resistance.

Finally, queer theory reminds us to be cautious of the homogenization of the LGBTQI+ community and to remember constantly the importance of other intersections of identity, privilege, and oppression. This sort of caution suggests the concept of intersectionality, which pushes forward theory, methodology, and action by engaging with the multiple social positions and hierarchies which an individual may possess or confront in daily life (Crenshaw, 1989; Collins, 1998; Collins \& Bilge, 2016). Merging queer and intersectional critical lenses uncovers and prompts exploration of different hierarchies, oppressions, and points of convergence, and subsequently creates space for new ways of being, solidarity, and action against the reproduction of social inequality (Medina, 2013). Central to queer theory and methodology is the foregrounding of the realities of queer people not only on the axis of sexuality or gender identity, but also on other axes of social positionality, in order to demonstrate the complexity of the intersections of oppressions (Alexander, 2017). Queer theory cohabitates with intersectionality and prompts a critical review of existing scholarship in international education. Simultaneously, it suggests new ways of conceiving knowledge production across the numerous variations of identity within the field. 
How can we use a queer theoretical lens?

A queer theoretical framework also promises to assist in producing new forms of knowledge and opening up a space for an entirely new, non-normative, non-dominant form of looking toward future research and action. Unique forms of looking at the world and the future elicit the production of knowledge, such as through a non-binary, non-heteronormative lens like a queer theoretical framework. Since queer theory demands that one continually reconceptualize how knowledge is produced, it is not possible to determine its endpoint beforehand (Sedgwick, 1990). It is crucial that the enterprise remain open-ended, because thinking in terms of queerness allows us to have the space and time to question our reality continuously-however toxic or imperfect it may currently be in its existing form (Halberstam, 2011; Muñoz, 1999, 2009). If queerness constitutes failure from the norm, then a queer perspective questions and creates new ways of being and knowing in the world (Halberstam, 2011). If the current reality is too hostile for those stigmatized by heteronormative society, queerness allows for a path to envision a new way of being in both physical and temporal spaces and the right to reject the status quo (Muñoz, 2009). Ultimately, I find this approach to be a powerful analytical tool in the search for new understanding since it forces us to pursue a more just future.

Queer theory, conceptualized as both a critical lens and praxis for social change, as I have argued here, lends itself not only to challenging the current order of society and ways of being, but also to carrying out that envisioned change. This duality suggests the notion of radical imagination. Radical imagination — the idea of thinking of the world as being a more just and equitable place for all, regardless of difference-constitutes not only the origin of social movements, but it inspires a movement for the reproduction of social progress (Haiven \& Khasnabish, 2014). In this essay, I augment my understanding of queer theory with the notion of radical imagination as developed by Haiven and Khasnabish (2014), especially vis-à-vis what they call "the research imaginary" or the complicated interaction and connection through ontological assumptions to epistemological approach, and then to research strategies (p. 217). They ask for a rejection of a linear approach which confines research to a static and predictable formula, and substitute an expanded model of research imagination, where the connections between these three parts are necessarily non-linear and produce a messy space where new ideas and collective actions generate. The authors further transpose notions of imagination, strategy, and tactics on the traditional tripod of ontology, epistemology, and methods. Within this transposition of producing academic knowledge (invocation) and working for social change (avocation), researchers can develop or "convoke a prefigurative methodology" that facilitates the community to ask and to build toward the future that they want to see in the present (Haiven \& Khasnabish, 2014, p. 254). Queer research fits into this approach because there is no predetermined pathway to carry out research beyond implementing the call for a better world that a queer positionality demands (Zeffiro \& Hogan, 2015; Muñoz, 2009). In this way, a queer theoretical perspective opens up new possibilities for imagining research in international education, just as in social movements, by raising the silenced voices of the LGBTQI+ persons marginalized within higher education and society and asking these individuals what sort of world they want to live in.

As I have mentioned, a queer approach to knowledge production is also praxis-based because of the necessity to understand and improve the current state of queer people. This approach is heavily influenced by Lather (1991) who proposes that praxis-based research offers a liberating 
pathway toward social change and transformation since it focuses on the quotidian knowledge generated by the individual and the community. My approach is also undergirded by the foundations of the concept of Research as Praxis, developed by Torres and Reyes (2011). They argue that a recognized flaw in postmodern thinking, where everything depends on context as an "absolute contingency," can then inhibit collective action by devaluing lived experiences as context specific and disconnected from larger social and structural inequities (p. 57). Within this approach to Research as Praxis, a path forward emerges in advancing not only our collective knowledge, but the approach also advocates for social action and transformation toward improving living conditions through the process of research.

\section{Structural Context: Macro-, Meso-, and Micro-levels}

One of the main goals for employing this conceptual framework is to help inform both theory and practice related to LGBTQI+ inclusion in the field of international education. Given the way I use a queer theoretical framework as a source of action and theory building, I argue that there needs to be an analysis of structural contexts (e.g. Englund, Olofsson, \& Price, 2018; Mathieson, 2011; Fanghanel, 2007; Zhu \& Engels, 2014) to carry out the social transformation as I described above. Through a rigorous examination of macro- (societal), meso- (institutional), and micro- (individual) levels of institutional contexts, this essay seeks to uncover new ways of understanding where the field is currently positioned and how standards of good practice can be adapted and implemented in other institutions. In this section, I explore how we can use public policy environments, institutional characteristics, and individual factors as a basis for analysis and building inclusive practices.

The macro-level context: Public policy environments.

I argue, along with others like Englund et al. (2018), that it is vital that higher education institutions, and arguably all public institutions, examine the legal and quasi-legal structural landscape created through public and institutional policies. I extend this examination to look at how this may impact the perceptions of inclusion for marginalized populations, especially the LGBTQI+ community. Given international education's unique connection to issues of citizenship and lawful protections and obligations through education that crosses borders, by having a better understanding of the public policy or macro-level environments in which institutions are operating, university officials are better equipped to attend to the unique needs of marginalized groups. Below, I outline a few areas for consideration of using public policy as a variable for understanding LGBTQI+ inclusion.

The policy landscape for protections for the LGBTQI+ population vary across the United States. During the second term of President Obama, the United States has seen two landmark decisions regarding marriage equality, United States v. Windsor (2013), which ruled that the federal government cannot exclude same-sex couples from the benefits and protections that married opposite-sex couples also receive, and Obergefell v. Hodges (2015), which held that all states must license a marriage between two people of the same sex and recognize other states' lawful licenses for the same. Despite these recognitions of rights under the Fifth and Fourteenth Amendments, respectively, as of September 2018, the United States has extreme variations in the individual states for protections for both sexual orientation and gender identity in employment, conversion therapy, education, hate crimes, housing, public accommodations, anti-bullying campaigns in schools, and transgender healthcare (Human Rights Campaign, 2018b). In turn, this impacts how institutions that 
operate within a state or local jurisdiction react or lead in protections for the LGBTQI+ community members.

The public policy environments are interwoven with institutional characteristics as universities enact policies that affect their own limited jurisdiction of the campus community. For example, some universities offer benefits and inclusive policies as a way of attracting LGBT employees (Shrader, 2016). In addition, in quantifying and qualifying policies and benefits that foster LGBTQI+ inclusion, we begin to understand where gaps in equitable treatment exist and provide opportunities for other institutions to follow suit. Some scholarship shows that inclusive policies for the LGBT community in institutions of higher education may improve campus climate perceptions (Rankin, 2003; O’Connell, Jackson, Karaoui, Rodriguez de Bittner, Chen, Echeverri, Vyas, Poirier, Lee, \& O’Neil, 2013). As a place of learning, scholarship, and work, institutions of higher education need to understand how the policy landscape that surrounds them and how their own internal policy structures may or may not foster LGBTQI+ inclusion within their communities.

Meso-level factors: Institutional characteristics.

While universities operate within a broad policy environment, not all universities within a single state or university system respond the same way. Institutional characteristics also affect the level of inclusion for LGBTQI+ people in universities. Several institutional, or meso-level, characteristics presented in the literature provide insights into potential factors related to the nexus of LGBTQI+ inclusion in higher education institutions. Research suggests a variety of institutional factors that affect LGBTQI+ inclusion on a particular campus and further, more focused, research on these factors will present a better understanding of LGBTQI+ inclusion in international education. Given that LGBTQ students experience marginalization differently in "traditionally heterogendered institutions" (Pryor, 2018, p. 33), understanding how different institutional characteristics intersect with LGBTQI+ inclusion will provide the field of international education with further sites of inquiry and practice.

For example, the attributes and demographics of a particular institution interact with perceptions of inclusion for the LGBTQI+ community. In one case, a small number of Historically Black colleges and universities (HBCUs) have undertaken efforts to increase the visibility of LGBT support through programs and activities, and some scholars argue that these colleges and universities offer unique sites for progress in this area of inclusion (Coleman, 2016; Mobley \& Johnson, 2015). Moreover, other types of institutions such as women's colleges in comparison to co-educational universities also provide unique opportunities for further research in queer inclusion. In another case, Freitas (2017) finds a significant difference between women's colleges and co-educational universities with regard to the experience of transgender students. At women's colleges, transgender students report more positive experiences, and the general student population reports more positive attitudes toward transgender students in comparison to co-educational universities (Freitas, 2017). Gathering further information about the attributes of the university, such as demographic-based data or other unique affiliations, will complete the picture as to how these institutional factors impact international education.

An understanding of the dynamic interactions between institutional characteristics, like the existence of LGBTQI+ inclusive counseling centers or libraries, will also provide practicable 
knowledge for international education because, as a field of practice, it intersects with units across a university with varied goals in support of a common mission of higher education. For example, McKinley, Luo, Wright, Kraus (2015) found that between 2008 and 2013 there was no significant increases in the prevalence of LGBT communication on counseling center websites, even less so for religious schools. The intersection between education abroad and counseling and health services in particular is an area to explore the extent to which institutions incorporate inclusive practices when providing care to LGBTQI+ community members. In terms of other institutional resources, such as libraries, Wexelbaum (2017) highlights that no research yet exists that supports the notion that libraries assist in retaining LGBT students, yet the author provides the groundwork for future research to investigate this intersection, wherein the library acts as a safe space for LGBT individuals to connect with resources. Since academic libraries are working with diverse international populations and students and faculty who access their resources worldwide, their role in bringing together LGBTQI+ community members and international education stakeholders remains underresearched.

In addition, there are inconsistent findings with respect to the relationship between knowing LGBT individuals and positive attitudes or support for inclusive policies in universities; however, this situation presents an opportunity for exploring intervening factors. One study shows that knowing LGBT individuals and awareness of the LGBT campus program results in a more positive attitude toward LGBT individuals (Worthen, 2014) and another shows that knowing an LGBT athlete is significantly associated with lower support for inclusive policies (Atteberry-Ash \& Woodford, 2018). In addition, Worthen (2014) finds that religiosity, Greek life membership, and being an athlete all negatively influence attitudes toward LGBT individuals. Further studies, conducted within a qualitative framework, should explore the nature of these relationships and the potential connections between group dynamics and affiliations with respect to inclusion in other campus related activities like athletics, religious groups, and Greek life. Understanding how these factors of group affiliation play a role in perceptions of campus climate will provide context for how LGBTQI+ inclusion occurs within international education programming at a particular university.

Micro-level factors: The power of the individual.

A third category of variables that may affect the level of LGBTQI+ inclusion in international education are individual, or micro-level, factors. Given the body of research on the crucial role stakeholders play in international education (Amey, 2010; Gieser, 2015; Lumby \& Foskett, 2016), future research should focus on ascertaining the connection between individual actors at the university and LGBTQI+ inclusion in that institution's international education initiatives and programming. Amey (2010) indicates the importance of champions or leaders who initiate, foster, and develop internationalization initiatives and partnerships within their institution. In developing internationalization strategies, it is crucial that both administrative leadership and faculty have personal involvement and that directives from administration integrate with grassroots support from the frontline professionals (Gieser, 2015; Neale, Spark, \& Carter, 2018). Similarly, the role of straight and queer allies supporting the inclusion of LGBTQI+ people and issues comes under discussion in studies related to specific disciplines; such as in accounting (Rumens, 2016a), in business schools (Rumens, 2016b), or in college athletic departments (Melton \& Cunningham, 2014). This research bridges the gap between the notion of champions for international education and the role of allies 
at the university for the inclusion of the LGBTQI+ community. I propose that further examination of the connections between individual actors and internationalization strategies will clarify the role of these actors in producing inclusive practices.

\section{Queer Theory Piercing Structural Context}

By converging, integrating, and overlaying the queer theoretical lens with this understanding of macro-, meso-, and micro-levels, I create a conceptual framework for evaluating and critiquing existing scholarship and positioning my call for more inclusive research and practices in international education. I use this framework to look at how we can use a queer theory lens to examine the intersections and points of overlap of the various micro, meso, and macro levels of analysis. For example, I perceive a queer theory lens could intersect with the macro-level through public policy in forms of legislation, regulation, and jurisdictional influences that may influence to what extent international education is supportive of LGBTQI+ people and issues without necessarily taking into account any institutional or individual characteristics or pressures. In contrast, piercing the macro and meso-levels offers an opportunity to look at how institutions located in a given jurisdiction are either influenced or influence the broader public policy environment with respect to LGBTQI+ inclusion. Finally, a queer theoretical perspective, as I have presented herein, engages each structural level and, at the same time, interrogates to what extent each level affects the others and allows us as practitioners and scholars to shift through varying levels of analysis.

To summarize, I believe that a queer theory perspective both clarifies and critiques each level, successively allowing knowledge to be gained and offering a reflective perspective on the whole picture. These levels are dynamic and their boundaries cross. This conceptual overlapping enacts the aforementioned queer-meaning making and world-making (Muñoz, 2009; Zeffiro \& Hogan, 2015; Alexander, 2017), either solely in one level or echoing through (Medina, 2013) and affecting the various levels of the systems involved.

\section{Examination of Current International Education Literature on LGBTQI+ Participants Through a Queer Theoretical Lens}

Conceptual Papers

Two conceptual papers (Oba \& Pope, 2013; Quach, Todd, Willis Hepp, Doneker Mancini, 2013) bring the under-researched area into focus and provide a basis for future scholarship. Both call for additional research on international queer students in the United States. In a theory-building article, Quach et al. (2013) focus on micro-level issues, calling for empirical research on sexual identity development, and its complications, for international gay, lesbian, and bisexual students from China. Quach et al. present general and sexual identity development models and critique them for limitations for GLB Chinese international students to begin building theory in this area. They specifically call for a qualitative empirical study with young Chinese students in the United States with the goal of establishing variables to test quantitatively and to make suggestions for psychological practice.

In the other conceptual paper, Oba and Pope (2013) focus on both meso- and micro-level issues calling for focused counseling and advocacy for LGBT international students to respond to the unique needs of this group. They review mental health literature on international students and on LGBT students to highlight four challenges for LGBT international students and four key 
concepts for mental health professionals to remember when working with that population, as the authors see them. Oba and Pope (2013) highlight that LGBT international students may have issues surrounding their sexual identity development, forming intimate relationships, healthy sexual practices, and challenges with returning to their home countries. In addition, Oba and Pope (2013) call for mental health professionals to be aware that international student may struggles with knowing what counseling services are on their campus, that working with the international student office is vital to connecting with the population, to understand what support structures exist in the community for LGBT people, and to be aware of the challenges when the students return to their home countries which may not be as welcoming or safe. This work should perhaps be categorized more as a practitioner guide because it fails to provide any methodology to study either actual experiences or evaluate proposed counseling interventions.

\section{Qualitative Studies}

Within my review of LGBTQI+ topics in international education, there are five peer-reviewed studies that employ a qualitative approach through the use of case studies as a method of analysis. Since I purposefully constrain my examination to peer-reviewed scholarly literature for this essay, I have not included a Master's thesis published in 2002, but it is important to mention as it appears to be the first time the notions of gay identity development were discussed along with an exploratory questionnaire to members of the international education community (Sanderson, 2002). None of the articles presented herein use a queer theoretical lens to examine the content of their inquiry and all focus on either the micro- or meso-level of analysis, both of which leave us with key areas for further study.

Blair (2011) uses a theoretical model of experiential learning in order to review a case study of a course on "Gay Paris: Culture, Society, and Urban Sexual Identity". The course both engaged students with gay and lesbian individuals and communities in Paris and analyzed the city as an urban place in which they are situated and living (p. 42). This particular study does not offer explicit research questions, but the author wants to look at how experiential learning activities in a specific cultural and geographical site, such as a city, can be used to facilitate support for intercultural learning, tolerance for diversity, and understanding the formation of identity (p. 39). To test the value of this theoretical approach, the author constructs a case study that focuses on the content of the course, its readings, and site visit activities that reinforce the principles of the National Society for Experiential Education and the students' awareness of the complexities in the process of mapping identity in the city. The author does not enumerate how many students participated in this course, but he qualitatively analyzes the students' evaluations and concludes that their reflections on the mapping exercises provided the students with authentic experiences relevant to intercultural learning. Emerging from this pedagogical focus, I recommend further inquiry that emphasizes a queer theoretical lens in order to delve into the relationship between experiential learning programs (i.e. a study abroad course such as "Gay Paris") with local LGBTQI+ communities and intercultural learning. For example, this particular study omits an explicitly intersectional understanding of the individuals with whom the students interacted and the students themselves, and, by only identifying groups as gay or lesbian, it neglects the richness of queer identity. In addition, the study fails to provide sufficient details on which factors the author used to evaluate the effectiveness of this particular case study and would be enhanced if explicit connections with institutional (meso-level) or public policy environments (macro-level) were addressed. 
Jubas (2015), in a qualitative case study focusing on meso-level factors, argues that, as the discourse surrounding internationalization of the university turns toward a non-specific idea of diversity, instead of specifically addressing ethnic, racial or national origin identities, the discussion fails to systematically address structural inequalities, including inequalities experienced by LGBT people. The author does not provide explicit research questions for this study. In this article Jubas (2015) identifies the international spread of a discourse on LGBT rights and identity along with the trend of a "globalizing university" in order to analyze policy texts from her institution, the University of Calgary and its Werklund School of Education (p. 61). The key finding, which Jubas (2015) emphasizes, is a neoliberal tendency to choose when to incorporate a discourse of rights for LGBT people in internationalization texts. The determining factor, as Jubas (2015) understands, is the intended audience of the text; a corporate audience receives a text with less emphasis on this discourse, whereas it may be emphasized in a publication intended for a faculty and student audience. The author admits that the study is preliminary and only focuses on a selection of internationalization texts from one particular Canadian university, but it proposes a methodology that is sensitive to a queer theoretical lens and its application in the discourse analysis of institutional texts on a larger scale.

In a subsequent article, again focusing on meso-level factors, the same author and another Canadian scholar, Jubas and White (2017) employ discourse analysis to examine equity and internationalization-oriented texts from their respective Canadian institutional homes. These texts include a Faculty-wide report, a strategic planning document, a website, and text on a wall of a campus building. Jubas and White (2017) examine how university texts, and the authors of these texts, use the word "diversity" in new ways as it moves from diversity offices and associated texts to international offices and their texts. The authors conclude with the implications this shift may have for LGBT people facing potentially heightened risks in the institution (p. 349). By using the "social meaning of keywords" as a theoretical and methodological lens, the authors take their home institutions - the University of Calgary and its Werklund School of Education and the University of New Brunswick and its Faculty of Education, respectively-as cases to examine the use of "diversity" in internationalization texts (p. 352). The study is somewhat limited by the fact that the University of New Brunswick does not have many publicly available texts that reference diversity and almost none that reference LGBT people. This limitation, however, allows for a critique of strategic internationalization texts at both institutions, which the authors analyze as a neoliberal interpretation of diversity as a factor of increasing marketplace competition. By focusing on LGBT people as a population, given their history of marginalization and often unique identity-based restrictions, Jubas and White (2017) conclude that we should (a) develop a better understanding of the potentially disturbing discourses around equity and internationalization in higher education and (b) identify where the negative consequences of such discourse need to be challenged. The authors call for additional research on how the discourse of internationalization and equity affect specific marginalized groups, like the LGBT community. Additionally, the authors recognize not only the importance of texts in the meso-level of institutions, but also in the larger macro-level public policy in organizations outside of higher education (p. 363). This article offers a first step toward future inquiry into cross-level analysis of internationalization texts that I believe will be a particularly fruitful avenue for research conducted through a queer theoretical lens.

In the final qualitative study that I identified, Brown (2016), employing an activity-theoretic 
approach, explores agency and identity in the study abroad experiences of a lesbian, feminist, nontraditional student from the United States in South Korea. By examining the experiences of a LGBTQI+ student in the study abroad context and setting the stage for future research on queer identity development for study abroad students, this article is a promising first step in uplifting queer voices into peer-reviewed research. Although this study focuses solely on the experiences of one particular individual, it is an important start to examining and understanding the connection between study abroad, goals of language acquisition, and attendant identity development. Future research and practice should explicitly explore how these individual, micro-level, experiences are connected to institutions and overarching social policies or norms that exist. A queer theoretical approach is essential in micro-level research in order to ensure that queer voices are represented in all of their diverse and intersecting fullness.

\section{Quantitative Studies}

Bryant and Soria's (2015) quantitative study of LGBTQI+ issues in international education focuses on micro-level issues. The authors examined a large survey, the Student Experience in the Research University (SERU), which is based at the Center for Studies of Higher Education at the University of California, Berkeley, for participation in study abroad (19,715 respondents from eight large, public research universities), searching for associations with sexual orientation and gender identity. The authors' research questions were looking to determine whether LGBTQQ (lesbian, gay, bisexual, transgender, questioning, or queer) students were significantly more or less likely to participate-after controlling for other demographic factors and college experiences-in study abroad with students' home campus, study abroad through another university, travel abroad for service learning or volunteerism, and travel abroad for cross-cultural experiences (p. 93). The authors ran logistic regression analyses for associations with these identities and particular kinds of study abroad options. Their data suggests,

that bisexual, gay or lesbian, questioning, self-identified queer, transgender, and genderqueer students were not significantly less likely to study or travel abroad in the four areas measured; instead, evidence from this sample suggests that these students may be more likely on average to participate in specific study or travel abroad experiences compared to their peers. (Bryant \& Soria, 2015, p. 100)

The authors found that bisexual, gay or lesbian students were more likely to study abroad on a program affiliated with their university than their peers, and results suggest bisexual and gay or lesbian students were significantly more likely to study abroad on a program affiliated with another university than their peers (p. 97). In addition, their models suggest that, compared to their peers, questioning, self-identified queer, and transgender students were more likely to travel abroad for work experience, volunteerism, or service learning, and that bisexual, questioning, and self-identified queer students were more likely to travel abroad for cross-cultural experiences (p. 98). Bryant and Soria (2015) admit to a "limited theoretical framework to position the study" and as such the authors suggest an exploration of their findings with a queer theoretical lens (p. 101). Further inquiry should ask why these students engaged in international education and what were the barriers for those who did not. It would be important to elevate the students' voices from the columns of variables and to place their stories into a descriptive context, so we could better understand their choices within their unique environment. 


\section{Queering Current International Education Practice?}

Within the professional practice of international education, issues related to diversity have received greater attention in recent years - the LGBTQI+ community in particular. For example, Diversity Abroad offers resources for professionals in international education as their work relates to students' intersecting backgrounds; however, many of their resources are only accessible to feepaying members, which highlights the need for institutional material support. Additionally, recent professional conferences have had themes focusing on issues related to diversity and inclusion. The world's largest nonprofit organization dedicated to international education and exchange, NAFSA: Association of International Educators (NAFSA), held a conference theme in 2018 of "Diverse Voices, Shared Commitment", and the Forum on Education Abroad hosted a conference in 2019 with the theme of "Broadening the Circle of Education Abroad". More specifically, a group of professionals at the University of Maryland hosted three conferences, in 2015, 2017 and 2019, called "Somewhere Over the Rainbow," which "is a professional development space on sexual orientation and gender identity in international education, including occasional in-person conferences as well as webinar series" (Somewhere Over the Rainbow, n.d.). Another group of professionals, NAFSA's Rainbow Special Interest Group (SIG), describes themselves as:

comprised of diverse members of NAFSA: Association of International Educators whose goals are to counsel international students and study abroad students who are lesbian, gay, bisexual, transgender, or queer; to support lesbian, gay, bisexual, transgender and queer professionals in international education; and to combat homophobia, heterosexism, and transphobia within NAFSA. (Rainbow SIG, 2019)

This group constitutes an informal collaborative effort of professionals who advocate for embedding queer praxis in the field. A possible direction for scholarly research as it relates to international education practice is an evaluation of accessibility of these resources for professionals. For example, scholars should evaluate levels of institutional support to engage in queer-focused professional development, which will elevate the queer voices that constitute these groups across the profession. In this way, research and praxis co-build solidarity with the aim of transforming international education.

Finally, practice-oriented material, written for professionals, not researchers or scholars, provides exploratory directives on how to support LGBTQI+ international and study abroad student populations; for example, Katz's (2008) article in the International Educator on LGBT International students or McCullers, Free, Gallant, Zeutenhorst, Finn, Parsons (n.d.) NAFSA: Association of International Educators webpage on "LGBTQ+ Student Advising Guide for Education Abroad Professionals." These publications, and others like them, offer a productive outlet for research-practitioners in the field of international education, who can transform the insights of a queer theoretical perspective into actionable recommendations for the field-recommendations that are grounded in rigorous research methodologies. Research-practitioners then constitute a groundswell of micro-level actors whose impact reverberates through meso- and macro-levels.

\section{Implications and Recommendations}

The vision of queer meaning-making and world-making is necessary to expand our understanding of LGBTQI+ inclusion in international education. In this section, I present important research and practice implications, which are intended for international education 
researchers, higher education practitioners, and administrators. What follows is a discussion of recommendations from the exploration of research and practice as I present in this essay.

\section{Implications for Practice}

Using a queer theoretical lens to examine the structural levels within which international education operates offers three broad recommendations for practitioners to implement. Speaking generally, individuals involved in international education must take into account the three structural levels in which their work reverberates. I list the following implications and recommendations not in order of importance, but from a cross-level perspective, starting from the macro-level, through the meso-, down to the micro-level. Since each level is interlinked, I recommend actions for stakeholders across the institution, international partners, professional organizations, and in some cases regulatory administrators.

First, practitioners should examine the macro-level or public policy environment within which they are situated. Once practitioners understand how their institutions must react to their legislative requirements and identify how these rules affect the LGBTQI+ community engaging in international education, they are well-situated to become advocates for broader policy changes to make their policies and practices more inclusive. The process of examination of these policies and advocacy for change requires input from the communities affected by the policies, namely the LGBTQI+ community. A queer theoretical lens informs this process by sensitively foregrounding queer voices (Alexander, 2017; Haiven \& Khasnabish, 2014, Torres \& Reyes, 2011). Furthermore, advocacy work should address legislative barriers to full inclusion of queer people in international education. If practitioners are unsure of where to begin with this process, I recommend that they partner with existing advocates at their institutions. While the external public policy environment in which each institution operates may range from seemingly very inclusive to very exclusive of LGBTQI+ people, I advise that all practitioners start with listening to the LGBTQI+ community that exists within their institution to understand how these macro-level factors affect their participation in international education.

Second, international education practitioners should continue the work of advocating for policy changes at the meso-level or within their own institutions to enhance inclusionary policies and practices for all. In this space, it will require individuals to examine how their particular institution executes its international education strategy to identify where it can target specific changes to its policies or practices. An initial step, as suggested by Jubas (2015) and Jubas and White (2017), is the critical examination of an institution's own internationalization texts, initiatives, and efforts with respect to queer inclusion. Again, I recommend that practitioners engage with the LGBTQI+ community to examine all of their policies and practices to account for unconscious bias that may exist and be difficult to readily identify (Dasgupta, 2013). By engaging in this meso-level scrutinization of one's own institution and change of policies and practices to being queer friendly and less hetero- and non-binary-normative, I believe engagement with international education experiences will increase, which supports the overarching goal of international education.

Third, leaders within international education must support and invest in their individual champions, at the micro-level, working day-to-day to carry out sustainable change. Given the need for personal involvement and the need for connection between administrators and grassroots 
advocates for international education efforts (Gieser, 2015; Neale, Spark, \& Carter, 2018), the field should develop more opportunities to raise the voices of individuals working on diversity, equity, and inclusion within international education. These individuals and groups should be supported so that their work is amplified across the field as a whole and we can build toward standards of good practice for people with diverse sexual orientations and gender identities. Practitioners should also be attentive to the insight of a queer theoretical lens when working with LGBTQI+ students to better understand their unique needs and barriers to entry into international education. This knowledge can then be used to effect change and improve the experiences of all (Lather, 1991; Torres \& Reyes, 2011). Therefore, it is at this micro-level that I believe the most sustainable change can occur and reverberate through the other structural levels.

\section{Recommendations for Research}

Through the critical review of the existing literature on the intersection between LGBTQI+ individuals and issues and international education using a queer theoretical analysis of structural levels, I present three broad research recommendations for the field to consider. A future scholar could use a variety of approaches to each of my recommendations below depending on their epistemological approach. I enumerate these pathways as starting points for pushing the field of international education toward greater equity in its policy and practice.

First, research should extend the work completed by Bryant and Soria (2015) to understand qualitatively why certain students pursue international education experiences and what the barriers are for those who do not. This research could be structured to examine the various factors at the different structural levels that affect an individual's participation in international education. On the basis of an understanding of these factors, it is possible to test to what extent these indicators explain the rates of participation or to contribute to the development of a queer theoretical lens as it relates to international education.

Second, scholars engaging in research on international education should expand their analysis of internationalization texts across institutions, building upon the work of Jubas (2015) and Jubas and White (2017), and highlight the importance of placing the texts within the larger macro-level public policy discussions that occur outside of higher education. One approach to this path of research is to conduct a comparative analysis across institutions of their internationalization texts with their public policy environments to uncover relationships that may exist for the inclusion or exclusion of the LGBTQI+ community. I believe this combination of macro- and meso-level analysis will lead to a deeper understanding of how the field of international education not only discusses queer issues, but also interacts with their public policy environments.

A third recommendation for furthering research on international education is the foregrounding of an intersectional understanding of the individuals who participate in or constitute the subjects of scholarly research, without further marginalizing populations already existing on the margins of society, universities, and institutions. By utilizing an intersectional lens in scholarly research (Collins, 1998; Collins \& Bilge, 2016; Crenshaw, 1989), we expand our notions of inclusion and create a more equitable field of international education. Scholars engaging in this pathway of research have the possibility of positing a variety of research questions that examine how individuals engage with international education. For example, a future scholar could expand upon the work of 
Brown (2016) and conduct additional qualitative research exploring how the intersection of various identities play a role in the international education experience. My explicit recommendation is that scholars should build into their research designs an intersectional understanding and approach by consciously including individuals who inhabit the margins of all social identity groups. This applies to research questions of all types and to all of the levels of structural analysis.

\section{Conclusion}

A clear need for additional and in-depth research on the intersection of LGBTQI+ inclusion in international education emerges by building off of the work of the scholars and practitioners currently engaged in this work and reinterpreting the state of research with a queer theoretical lens. While little is known about this nexus of people, institutions, and associated policy environments, existing research calls for particular consideration of LGBTQI+ diversity within the strategies and programs of international education. The small body of literature on LGBTQI+ diversity in international education primarily focuses on either the micro- or meso- structural levels of analysis without any focus on the macro-level policies or a combination of micro-, meso-, and macro-levels. A path forward for potential scholarship shows itself within a new queer future, which pushes for a unique and radically transformative understanding and resistance to the complexity of structural contexts. With this background and lens, future research will uncover the relationships between these varied levels of context to inform knowledge production and institutional practices.

\section{References}

Alexander, B. K. (2017). Queer/Quare theory: Worldmaking and methodologies. In N. K. Denzin \& Y. S. Lincoln (Eds.), The SAGE handbook of qualitative research (pp. 108-150). Thousand Oaks: Sage Publications.

Berghman, J. (1995). Social exclusion in Europe: Policy context and analytical framework. In G. Room (Ed.), Beyond the thresholds: The measurement and analysis of social exclusion, (10-20). Bristol, UK: Policy Press.

Bilodeau, B. L., \& Renn, K. A. (2005). Analysis of LGBT identity development models and implications for practice. New Directions for Student Services, 2005(111), 25-39. https://doi.org/10.1002/ss.171

Blair, S. (2011). Study abroad and the city: Mapping urban identity. Frontiers: The Interdisciplinary Journal of Study Abroad, 20, 37-54.

Blalock, N. (2015). More than me. In A. J. Jolivétte (Ed.), Research justice: Methodologies for social change. (pp. 57-62). Chicago, Illinois: Policy Press.

Brown, L. (2016). An activity-theoretic study of agency and identity in the study abroad experiences of a lesbian nontraditional learner of Korean. Applied Linguistics, 37(6), 808-827.

Brux, J. M., \& Fry, B. (2010). Multicultural students in study abroad: Their interests, their issues, and their constraints. Journal of Studies in International Education, 14(5), 508-527. doi: $10.1177 / 1028315309342486$

Bryant, K. M., \& Soria, K. M. (2015). College students' sexual orientation, gender identity, and participation in study abroad. Frontiers: The Interdisciplinary Journal of Study Abroad, 25, 91-106.

Capobianco, S., Chen, X., Líppez-De Castro, S., \& Rubaii, N. (2018). Enhancing global and intercultural competencies in Master of Public Administration classes: Assessing alternative approaches to incorporating cultures and languages. Teaching Public Administration, 36(2), 178-200. https://doi.org/10.1177/0144739417753031

Carpenter, C. S. (2008). Sexual orientation and outcomes in college. Economics of Education Review, 28, 693-703. doi: 10.1016/j.econedurev.2007.10.010

Collins, P. H. (1998). It's all in the family: Intersections of gender, race, and nation. Hypatia, 13(3), 6282. 
Collins, P. H., \& Bilge, S. (2016). Intersectionality. Cambridge, UK: Polity Press.

Crenshaw, K. (1989). Demarginalizing the intersection of race and sex: A black feminist critique of antidiscrimination doctrine, feminist theory and antiracist politics. University of Chicago Legal Forum, 1989(1). Retrieved from https://chicagounbound.uchicago.edu/uclf/vol1989/iss1/8

Curtis, T., \& Ledgerwood, J.R. (2017). Students' motivations, perceived benefits and constraints toward study abroad and other international education opportunities. Journal of International Education in Business, 11(1), 63-78. doi: 10.1108/JIEB-01-2017-0002

Dasgupta, N. (2013). Implicit attitudes and beliefs adapt to situations: A decade of research on the malleability of implicit prejudice, stereotypes, and the self-Concept. In Advances in Experimental Social Psychology, 47, (pp. 233-279). Academic Press Inc. https://doi.org/10.1016/B978-0-12407236-7.00005-X

Englund, C., Olofsson, A.D. \& Price, L. (2018). Higher Education, 76(6), 1051-1069. https://doi.org/10.1007/s10734-018-0254-1

Fanghanel, J. (2007). Local responses to institutional policy: a discursive approach to positioning. Studies in Higher Education, 32(2), 187-205. https://doi.org/10.1080/03075070701267244.

Fine, M. (2015) Decolonizing knowledge: Toward a critical research justice praxis in the urban sphere. In A. J. Jolivétte (Ed.), Research justice: Methodologies for social change. (pp. 199-204). Chicago, Illinois: Policy Press.

Foucault, M. (1978). The history of sexuality. (1st American ed.). New York: Pantheon Books.

Gates, G. J. (2011). How many people are lesbian, gay, bisexual, and transgender? Retrieved from: https://williamsinstitute.law.ucla.edu/wp-content/uploads/Gates-How-Many-People-LGBT-Apr2011.pdf

Gates, G. J. (2017). "In US, More Adults Identifying as LGBT". Gallup News. Retrieved from: http://news.gallup.com/poll/201731/lgbt-identification-rises.aspx

Gieser, J. D. (2015). A sociocultural investigation of identity: How students navigate the study abroad experience. Journal of College Student Development, 56(6), 637-643.

Halberstam, J. (2011). The queer art of failure. Durham, NC: Duke University Press. Retrieved from doi:10.1215/9780822394358

Hameister, B., Mathews, P., Hosley, N., \& Groff, M. C. (1999). College students with disabilities and study abroad: Implications for international education staff. Frontiers: The Interdisciplinary Journal of Study Abroad, 5(2), 81-100.

Institute of International Education. (2018). "Generation study abroad". Retrieved from https://www.iie.org/Programs/Generation-Study-Abroad

Institute of International Education. (2017a). "Destinations." Open Doors Report on International Educational Exchange. Retrieved from_https://www.iie.org/Research-and-Insights/OpenDoors/Data/US-Study-Abroad/Destinations

Institute of International Education. (2017b). "Enrollment." Open Doors Report on International Educational Exchange. Retrieved from https://www.iie.org/Research-and-Insights/OpenDoors/Data/International-Students/Enrollment Institute of International Education. (2017a). "Destinations." Open Doors Report on International Educational Exchange. Retrieved from https://www.iie.org/Research-and-Insights/Open-Doors/Data/US-Study-Abroad/Destinations

Institute of International Education. (2017c). "Student profile." Open Doors Report on International Educational Exchange. Retrieved from https://www.iie.org/Research-and-Insights/OpenDoors/Data/US-Study-Abroad/Student-Profile

Institute of International Education. (2018a). A world on the move: Trends in global student mobility (Issue No. 2). Retrieved from https://www.iie.org/Research-and-Insights/Publications/A-World-onthe-Move

Institute of International Education. (2018b). "Generation study abroad". Retrieved from https://www.iie.org/Programs/Generation-Study-Abroad

Knight, J. (2004). Internationalization remodeled: Definition, approaches, and rationales. Journal of Studies in International Education, 8(1), 5-31. https://doi.org/10.1177/1028315303260832 
Jubas, K. (2015). Discursive inconvenience: The dis/appearing rhetoric of LGBT rights in post-secondary internationalization texts. Canadian Journal of Educational Administration and Policy, 173, 50-72.

Jubas, K., \& White, M. (2017). Marketing equity: "Diversity"as keyword for internationally engaged postsecondary institutions. Review of Education, Pedagogy, and Cultural Studies, 39(4), 349-366. doi: 10.1080/10714413.207.1344507

Larsen, M. A., \& Searle, M. J. (2017). International service learning and critical global citizenship: A cross-case study of a Canadian teacher education alternative practicum. Teaching and teacher education, 63, 196-205. doi: 10.1016/j.tate.2016.12.011

Lincoln, Y. S., Lynham, S. A., \& Guba, E. G. (2017). Paradigmatic controversies, contradictions, and emerging confluences, revisited. In N. K. Denzin \& Y. S. Lincoln (Eds.), The SAGE handbook of qualitative research (pp. 108-150). Thousand Oaks: Sage Publications.

Luther, J. D. (2017). 12: Queer theory. Year's Work in Critical \& Cultural Theory, 25(1), 231-251. https://doi.org/10.1093/ywcct/mbx012

Deardorff, D. J. (2017). The BIG picture: Reflections on the role of international educational exchange in peace and understanding. In J. Mathews-Aydinli (Ed.). International education exchanges and intercultural understanding: Promoting peace and global relations. Cham, Switzerland: Palgrave Macmillan.

Mathieson, S. (2011). Disciplinary cultures of teaching and learning as socially situated practice: rethinking the space between social constructivism and epistemological essentialism from the South African experience. Higher Education, 63(5), 549-564. https://doi.org/10.1007/s10734-011-9458-3.

Mayo, C. (2007). Queering foundations: Queer and lesbian, gay, bisexual, and transgender educational research. Review of Research in Education, 31, 79-94.

Medina, J. (2003). Identity trouble: Disidentification and the problem of difference. Philosophy \& Social Criticism, 29(6), 655-680.

Medina, J. (2013). The epistemology of resistance: gender and racial oppression, epistemic injustice, and resistant imaginations. New York: Oxford University Press.

Mobley, S. D., \& Johnson, J. M. (2015). The role of HBCUs in addressing the unique needs of LGBT students. New Directions for Higher Education, 170, 79-89.

Muñoz, Jose. (1999). Disidentifications: Queers of color and the performance of politics. Minneapolis: University of Minnesota Press.

Muñoz, J. E. (2009). Cruising utopia: the then and there of queer futurity. New York: New York University Press. Retrieved from http://ebookcentral.proquest.com/lib/cornell/detail.action?docID $=865693$

Oba, Y., \& Pope, M. (2013). Counseling and advocacy with LGBT international students. Journal of LGBT Issues in Counseling; Abingdon, 7(2), 185.

Otero, M. S. (2008). The socio-economic background of Erasmus students: A trend towards wider inclusion? International Review of Education, 54(2), 135-154.

Quach, A. S., Todd, M. E., Willis Hepp, B., \& Doneker Mancini, K. L. (2013). Conceptualizing sexual identity development: Implications for GLB chinese international students. Journal of GLBT Family Studies, 9(3), 254-272. doi:10.1080/1550428X.2013.781908

Rainbow SIG. (2019). Welcome to the Rainbow SIG website! Retrieved from http://www.rainbowsig.org/

Rankin, S. R. (2003). Campus Climate for Gay, Lesbian, Bisexual, and Transgender People: A National Perspective. New York: The National Gay and Lesbian Task Force Policy Institute. Retrieved from: http://thetaskforce.org/downloads/reports/reports/CampusClimate.pdf

Renn, K. A. (2010). LGBT and queer research in higher education: The state and status of the field. Educational Researcher, 39(2), 132-141. Retrieved from http://www.jstor.org/stable/27764565

Same-sex couple and LGBT demographic data interactive. (2016). Los Angeles, CA: The Williams Institute, UCLA School of Law. Retrieved from https://williamsinstitute.law.ucla.edu/visualization/lgbt-stats/

Scheib, M., \& Mitchell, M. (2008). Awaiting a world experience no longer: It's time for all students with disabilities to go overseas. In T. Berberi, E. C. Hamilton, \& I. M. Sutherland (Eds.). Worlds apart?: 
Disability and foreign language learning. New Haven, CT: Yale University Press.

Sedgwick, E. K. (1990). Epistemology of the closet. Berkeley: University of California Press.

Smith, L. T. (2015) Decolonizing knowledge: Toward a critical indigenous Research Justice praxis. In A. J. Jolivétte (Ed.), Research justice: Methodologies for social change. (pp. 205-210). Chicago, Illinois: Policy Press.

Somewhere Over the Rainbow (n.d.) Retrieved from https://sites.google.com/view/sotr/home?authuser=0

Stewart, B. and Kendrick, K. (2019). "Hard to find": Information barriers among LGBT college students. Aslib Journal of Information Management, 71(5), 601-617. doi:10.1108/AJIM-02-2019-0040

Stone, D. (2012). Policy paradox: The art of political decision making (3rd ed.). New York, NY: W. W. Norton \& Company, Inc.

Stroud, A. (2010). Who plans (not) to study abroad? An examination of U.S. student intent. Journal of Studies in International Education, 20(5), 1-18. doi:10.1177/1028315309357942

Teman, E. D., \& Lahman, M. K. E. (2012). Broom closet or fish bowl? An ethnographic exploration of a university Queer Center and oneself. Qualitative Inquiry, 18(4), 341-354. https://doi.org/10.1177/1077800411433548

Torres, V., Jones, S. R., \& Renn, K. A. (2009). Identity development theories in student affairs: Origins, current status, and new approaches. Journal of College Student Development, 50(6), 577-596.

Torres, M. N., \& Reyes, L. V. (2011). Research as praxis: Democratizing education epistemologies. New York: Peter Lang.

Zeffiro, A., \& Hogan, M. (2015). Queered by the archive: No More Potlucks and the activist potential of archival theory. In A. J. Jolivétte (Ed.), Research justice: Methodologies for social change. (pp. 4355). Chicago, Illinois: Policy Press.

Zhu, C., \& Engels, N. (2014). Organizational culture and instructional innovations in higher education. Educational Management Administration \& Leadership, 42(1), 136-158. https://doi.org/10.1177/1741143213499253.

Ziemba, R. Sarkar, N. J., Pickus, B., Dallwig, A, Wan, J.A., \& Alcindor, H. (2016). Using international videoconferencing to extend the global reach of community health nursing education. Public Health Nursing, 33(4), 360-370. 